\title{
MEDIAÇÃO COMO PRÁTICA DE RECONHECIMENTO DA PESSOA HUMANA
}

\section{MEDIATION AS A TOOL OF THE HUMAN BEING ACKNOWLEDGEMENT}

\author{
${ }^{1}$ Adriana Silva Maillart \\ ${ }^{2}$ Nelson Laginestra Junior
}

\section{RESUMO}

O objetivo deste artigo é demonstrar que a mediação não contempla como finalidade exclusiva a resolução de conflitos; alarga-se para abarcar o aspecto denominado reconhecimento da pessoa humana em seu sentido antropológico, escapando da mera definição jurídica de indivíduo portador de direitos e obrigações. O reconhecimento do outro, adotado na perspectiva da gestão do conflito, contribui não só para que as controvérsias afastem-se do resultado de soma-zero, resultante da concepção tradicional de Justiça, mas também para que os indivíduos e a sociedade, adotando ações orientadas para o entendimento mútuo, alcancem sua autonomia e a preservação das relações interpessoais, na verdadeira acepção coexistencial de Justiça. Trata-se de um artigo de caráter exploratório, que utilizar- se-á de técnica de pesquisa bibliográfica e da análise sociológica do Direito, utilizando-se do método sistêmico de abordagem.

Palavras-chave: Mediação, Gestão de conflito, Autonomia social

\begin{abstract}
The goal of this article is to demonstrate that mediation don't contemplate exclusively as purpose the resolution of conflicts; gets expanded to receive the aspect denominated as recognition of the human person in its anthropologic meaning, escaping from the mere legal definition of the owner of rights and obligations. The recognition of the other, adopted in the context of conflict management, contributes not only to the controversy back it up to the result of zero-sum resulting from the traditional concept of Justice, but also to individuals and society by adopting targeted actions for mutual understanding, achieve their independence, but also preserving interpersonal and social relations, in the true sense of coexistential justice. It is an exploratory article, which employ bibliographic research technique and social analysis of Law and also the systemic method of approach.
\end{abstract}

Keywords/Palabras-claves/Mots-clés: Mediation, Conflict managing, Social autonomy

\footnotetext{
${ }^{1}$ Doutora em Direito pela Universidade Federal de Santa Catarina - UFSC, Florianópolis, (Brasil). Coordenadora do Curso de Direito e Professora do Corpo Permanente e Pesquisadora do Programa de Mestrado em Direito da Universidade Nove de Julho - Uninove. E-mail: adrissilva@gmail.com

${ }^{2}$ Mestrando em Justiça, Empresa e Sustentabilidade pela Universidade Nove de Julho - Uninove, São Paulo, (Brasil). Professor das Disciplinas Direito Penal e Direito Processual Penal pela Universidade Nove de Julho UNINOVE, São Paulo. E-mail: nlaginestra@uol.com.br
} 


\section{INTRODUÇÃO}

A proposta deste estudo traz consigo uma advertência desde logo apresentada àqueles que dedicarem seu tempo a esta leitura; não serão aqui apresentadas nem analisadas fórmulas ou teorias relativas ao comportamento do profissional mediador no curso de sua função. Não obstante a importância dos manuais, e são muitas e excelentes as abordagens teóricas a respeito das aplicações práticas afeitas ao tema, e das várias vertentes do pensamento responsáveis por desenvolver um cabedal de regras importantíssimas à consecução dos trabalhos de mediação, tem-se, por ora, nesta análise, a pretensão de demonstrar a importância do "reconhecimento" da pessoa humana na construção de métodos autocompositivos de resolução de conflitos.

Dessa forma, pretende-se apresentar ao leitor um sentido mais humanizado e prático contraposto à ortodoxia da exegese jurídica. Mas não haverá de se abandonar, por completo, a juridicidade do tema, apenas opta-se pelo olhar dirigido a situações não preconcebidas, nem às receitas preexistentes.

Percebe-se na mediação uma forma de reaproximação com o outro e um reconhecimento do próprio eu, uma vez que a partes devem afastar sua visão egoística sobre o conflito, abrindose para o diálogo e afastando o resultado soma-zero, tão culturalmente promovido pelo ideário tradicional de justiça.

Espera-se, ao final, contribuir no sentido da construção de um novo paradigma a potencializar a capacidade de autodeterminação e autonomia dos indivíduos na sociedade contemporânea.

Este artigo possui caráter exploratório, utilizando-se de técnica de pesquisa bibliográfica e da análise sociológica do Direito, adotando o método sistêmico de abordagem.

\section{RECONHECIMENTO E PERCEPÇÃO DO “OUTRO”: FUNDAMENTO DA RELAÇÃO DIALÓGICA}

$\mathrm{Na}$ seara dos relacionamentos interpessoais pode-se distinguir dois caminhos como opções à resolução de conflitos: a trilha do diálogo, da tentativa de compreensão do ponto de vista alheio, do exercício do saber ouvir e, principalmente, refletir, acerca dos argumentos do interlocutor; o segundo caminho indica lançar mão da potência, do poderio capaz de levar a uma solução marcada pela violência. Entenda-se, no caso, não apenas a violência física, mas 
principalmente aquela proveniente da força coercitiva apta a obrigar alguém a fazer ou deixar de fazer algo ${ }^{1}$.

Quando um direito é lesado, abre-se um leque de opções para que os indivíduos solucionem suas controvérsias, e cada forma de resolução possui um perfil mais ou menos estabelecido de qual postura as partes adotarão na tentativa de por fim ao litígio e qual postura adotará a terceira parte envolvida na resolução do conflito.

Segundo Boaventura de Souza Santos, Maria Manuel Leitão Marques e João Pedroso, (2015):

\begin{abstract}
Num complexo sistema de feedback, a avaliação da dimensão da lesão e os objetivos da reparação estão, como dissemos, em íntima interação com os mecanismos de resolução à disposição do lesado e com a capacidade deste ou do próprio mecanismo para convocar ao processo de resolução o causador do dano. Pode-se dizer que todas as sociedades minimamente complexas têm à disposição dos litigantes um conjunto mais ou menos numeroso de mecanismos de resolução dos litígios, entendendo como tal todas as instâncias suscetíveis de funcionar como terceira parte, ou seja, como instâncias decisórias exteriores às partes em litígio. Variam enormemente segundo a oficialidade, a formalidade, a acessibilidade, a especialização, a eficácia, a eficiência, a distância cultural etc.
\end{abstract}

A terceira parte, mencionada por estes autores, pode ter maior ingerência na decisão da lide, conforme seu escopo. Exemplo disto são as formas heterocompositivas de soluções de controvérsias que dão poder de dizer o direito a um pessoa legitimada pelo Estado (jurisdição estatal) ou, por vontade das partes, quando tratarem-se de direitos patrimoniais disponíveis a terceiras pessoas alheias ao conflito e indicadas de comum acordo pelas partes (arbitragem).

Estes meios, como se pode depreender, possuem como fim maior dar uma decisão ao caso (pelo proferimento de uma sentença) e não possuem o intuito primordial de resolver o conflito propriamente dito, pelo próprio caráter dos dispositivos heterocompositivos.

A arbitragem, por ser instituída e baseada praticamente em todo seu contexto pela autonomia das partes, ainda permite que as partes possuam maior envolvimento na construção da resolução da disputa, mas ainda assim possui sua característica acentuada de meio heterocompositivo.

\footnotetext{
${ }^{1}$ Importante lembrar, entretanto, que a uma das primeiras formas de solução de litígios, principalmente adotadas pelas sociedades primitivas, é a autotutela, que permite a imposição da decisão por uma das partes à outra. A autotutela, apesar de seu caráter primitivo, ainda é aplicada excepcionalmente, havendo alguns casos específicos assegurados no Direito brasileiro, a exemplo do direito à retenção (Código Civil - CC -, arts. 516, 772, 939, 1.199, 1.130, 1.131, 1.279 e 1.315), o "desforço imediato" (CC, art. 502), o penhor legal (CC, art. 776), o direito de cortar raízes e ramos de árvores limítrofes que ultrapassem a extrema do prédio (CC, art. 558), a autoexecutoriedade das decisões administrativas; sob certo aspecto, podem-se incluir entre essas exceções o poder estatal de efetuar prisões em flagrante (CPP, art. 301) e os atos que, embora tipificados como crime, sejam realizados em legítima defesa ou estado de necessidade (CP, arts. 24 e 25; CC, arts. 160, 1.519 e 1.520).
} 
Por outro lado, o Poder Judiciário possui um caráter mais rígido, concedendo ao Estado-juiz o poder de decisão². Nas palavras de Boaventura de Souza Santos, Maria Manuel Leitão Marques e João Pedroso (2015), "em geral, os tribunais tendem a ocupar um dos extremos em muitas dessas dimensões. De todos os mecanismos de resolução de litígios disponíveis tendem a ser os mais oficiais, os mais formais, os mais especializados ${ }^{3}$ e os mais inacessíveis".

Como outra possibilidade há a autocomposição, caracterizada pela solução do litígio por ato das próprias partes, sem emprego de violência, pelo acordo, das quais se destacam, dentre outros, a transação, a conciliação ${ }^{4}$ e a mediação ${ }^{5}$, esta última objeto de nossa pesquisa. Aqui a terceira parte, quando envolvida ${ }^{6}$, possui papel primordial de aproximar as partes e

\footnotetext{
${ }^{2}$ Com a promulgação do Novo Código de Processo Civil (Lei n. 13.105, de 16 de março de 2015), ainda em vacatio legis, houve uma preocupação de inserir dispositivos que permitam que as partes possam utilizar-se da conciliação e mediação, inclusive em âmbito judicial, como pode-se depreender num dos primeiros artigos do Código: "art. 3. O Estado promoverá, sempre que possível, a solução consensual dos conflitos. Apesar da ainda resistente aceitação de parte dos operadores jurídicos sobre estes dispositivos do Novo Código, abre-se a oportunidade para que as partes contribuam para a construção da solução da lide, criando uma cultura menos paternalista da simples entrega da tutela jurisdicional.

${ }^{3} \mathrm{Na}$ atualidade, a especialização do Poder Judiciário entra em debate, pois, em muitos setores, o Judiciário encontra-se defasado com relação as necessidades da sociedade. Como especifica Adriana S. Silva (2005, p. 114-116): "outro problema encontrado pelo Judiciário é a dificuldade de adaptação às novas realidades da sociedade. A sociedade tem avançado mais do que o direito pode acompanhar. O sistema jurídico brasileiro, baseado em pilares positivistas, entrava muito a decisão dos litígios. Não existem normas específicas para todas as situações e, apesar de o Código Civil autorizar tanto a aplicação da analogia, do costume e dos princípios gerais do direito e, em casos específicos, quanto o uso da eqüidade, outra barreira é encontrada: a mentalidade do juiz". Enquanto não houver o dinamismo do Poder Judiciário frente ao surgimento de novos direitos e, consequentemente, de novos conflitos, cria-se um obstáculo ao desempenho do Judiciário, tornando-se um generalista no tratamento das "enfermidades" da sociedade ao invés de um especialista.

${ }^{4}$ Talvez tentando solucionar a confusão sobre a distinção entre os institutos da mediação e conciliação, que aparece tanto na literatura quanto na prática, o Novo Código de Processo Civil, ao definir o conceito de mediador e de conciliador, trouxe algumas diferenças básicas destes dois institutos, como pode-se verificar nos textos dos parágrafos $2^{\circ}$ e $3^{\circ}$ do art. 165 . O parágrafo $2^{\circ}$, do mencionado artigo, determina que: "O conciliador, que atuará preferencialmente nos casos em que não houver vínculo anterior entre as partes, poderá sugerir soluções para o litígio, sendo vedada a utilização de qualquer tipo de constrangimento ou intimidação para que as partes conciliem. Enquanto que o parágrafo $3^{\circ}$ dispõe que: "O mediador, que atuará preferencialmente nos casos em que houver vínculo anterior entre as partes, auxiliará aos interessados a compreender as questões e os interesses em conflito, de modo que eles possam, pelo restabelecimento da comunicação, identificar, por si próprios, soluções consensuais que gerem benefícios mútuos".

${ }^{5}$ Luiz Alberto Warat (2004), analisando o aspecto sociológico dos três institutos, assevera que: "a conciliação e a transação podem, num primeiro momento, se parecer com a mediação, mas as diferenças são enormes. Ao contrário da mediação, essas duas técnicas não trabalham o conflito $\mathrm{e}$, portanto, não o transformam. $\mathrm{O}$ conciliador exerce a função de "negociador do litígio", reduzindo a relação conflituosa a uma mercadoria. A conciliação faz com que os envolvidos acabem abrindo mão de alguma coisa para encerrar a questão. Mas, o conflito permanece inalterado. A mediação é uma proposta transformadora do conflito, porque não busca a sua decisão por um terceiro, mas sim a resolução do problema pelas próprias partes, que recebem ajuda do mediador para administrar a questão. Nesse caso não há preocupações com o litígio, ou seja, com a verdade formal contida nos autos ou com a formulação de um acordo. O objetivo principal da mediação é ajudar os envolvidos a redimensionarem o conflito, entendido como conjunto de condições psicológicas, culturais e sociais que determinam um choque de atitudes e interesses no relacionamento das partes. O mediador exerce a função de ajudar as pessoas a reconstruírem simbolicamente a relação conflituosa".

${ }^{6} \mathrm{Na}$ transação, a terceira parte é dispensável, pois o que escopo maior deste instituto é o acordo, em que as partes mediante concessões mútuas previnem ou terminam o litígio.
} 
apenas facilitar a comunicação para que as próprias partes resolvam sua controvérsia, proporcionando o desenvolvimento da autonomia e a autodeterminação de cada indivíduo envolvido no conflito.

Quando se pensa no instituto da mediação como instrumento ou meio adequado a uma solução estável e duradoura, a opção pela violência e falta de diálogo referida no início deste tópico há de esvanecer-se completamente do rol das possibilidades. O motivo é singelo; "a busca dialógica de uma solução não violenta é o reconhecimento da pessoa" (ALMEIDA, 2014, p. 2). Mas “como" se reconhece a pessoa? Destaca-se o verbo aqui empregado no sentido de perceber, admitir ou aceitar a condição de "pessoa" com a qual estabelecer-se-á o diálogo.

A ideia é contrapor ao paradigma cultural do "ganhar-perder" uma força oposta capaz de romper a lógica fossilizada pelo determinismo binário. As "soluções" decorrentes de disputas aparentemente encerradas, atribuindo "razão" à parte "ganhadora", e estabelecendo um pesado ônus à parte "perdedora" desvanecem a gama de possíveis resultados de caráter mais definitivo acerca da contenda. A consequência mais funesta revelar-se-ia, nessas circunstâncias, pela potencialização dos conflitos interpessoais; a relação entre os indivíduos envolvidos na disputa - que já era ruim antes da imposição de determinada "solução" -, tende a degenerar-se ainda mais com a plena insatisfação de uma das partes (SCHNITMAN, 1999).

No contexto da resolução de litígios, priorizar o método apto a afastar o empobrecido resultado que proclama um "vencedor" e um "vencido" significa atender ou reconhecer a singularidade do "eu" alheio, a priori. Há de se considerar a possibilidade de um "ganho conjunto" combinado a uma "divisão proporcional de perdas" a legimimar efetivamente a solução, construída pelas próprias personagens do conflito. Trata-se tão-somente de abrir mão das diferenças geradoras da disputa, tornando prioritária a busca de um ponto de tangência, de um resvalar de intereses comuns. Não há falar-se em um "encobrimento" de pontos de vista opostos - afinal, se não existissem divergências, não haveria conflito.

Dar cabo ao litígio, atingindo-se bom têrmo a contemplar os interesses individuais dos divergentes implica inverter a lógica binária do paradigma "ganhador-perdedor"; significa colocar de ponta cabeça essa lógica. Ao invés de se ressaltarem as controvérsias, ao sinal de largada dos trabalhos de mediação a primeira missão das partes em conflito - e responsabilidade intrínseca do mediador - diz com a detecção dos pontos convergentes. A divergência não há de ser esquecida, mas deve ser colocada de lado momentaneamente, ficar no modo stand by, ser reservada, hibernar. 
A descoberta de anseios comuns em uma disputa não raro é afastada, haja vista a justificativa simplista a encetar o bordão da "verdade absoluta" pela assertiva de que se há conflito de interesses, inimaginável o reconhecimento de pontos de convergência entre os adversos. É como se os interesses de cada uma das partes compusesse cada qual uma semirreta, ambas paralelas, com ponto de origem no nascedouro do conflito e nenhuma perspectiva de solução compartilhada, a confirmar a inexorável tese da geometria clássica: duas semirretas paralelas jamais se encontram.

Porém, o dogma matemático desaba hodiernamente sob os auspícios de novas teorias reveladoras de momento e de lugar nos quais se encontrariam as paralelas. Tal evento extraordinário se daria no infinito. Neste ponto da leitura, há de surgir uma contorsão, mais sarcástica que irônica, de canto de lábios, no cético leitor. Reação compreensível, mas à qual pede-se licença para responder com as palavras do poeta Mário Quintana: "Se as coisas são inatingíveis... ora! Não é motivo para não querê-las... Que tristes os caminhos, se não fora a presença distante das estrelas!”

A proposição de novas perspectivas a subverter a ordem posta nos sistemas tradicionais de resolução de conflitos por óbvio pressupõe uma disposição íntima das partes na perseguição de resultados construídos sob o menor grau de onerosidade viável a cada um dos partícipes. A forma na qual se desenvolve a comunicação no caminho da busca de soluções opera diretamente na qualidade do desfecho. Comunicar-se extrapola o mero binômio “transmissão de mensagens entre um emissor e um receptor". (SCHNITMAN, 1999, p. 24). A comunicação engloba um leque de ações verbais e não-verbais para conhecer e fazer-se conhecer.

Aos optantes dos novos métodos de pacificação de disputas está reservado o difícil exercício da paciência. Ausente tal virtude no âmago do comportamento de cada sujeito do conflito, impossível desenhar-se solução fincada, justamente, na perspectiva de paz duradoura. Ocorre no mais das vezes que só se reserva paciência àquilo ou a quem atribui-se valor elevado, respeito, consideração. A paciência é proporcional à importância reservada para determinadas coisas ou pessoas. Só há paciência, portanto, quando há reconhecimento de determinadas qualidades essenciais que tornam elevado o status do bem ou da própria condição humana.

A cultura contenciosa presente no desenrrolar formal dos processos judiciais tende a distorcer, por vezes, o sentimento de realização do justo. Se uma das partes é "vencedora", a outra, necessariamente "perde", não obstante os casos de acolhimento parcial daquilo que é pleiteado, pois, mesmo nestas hipóteses, impõe-se, coercitivamente, determinada obrigação a 
uma das partes. A árdua tarefa de dizer o direito e tornar exigível a sua aplicação, em que pese a sua conveniência para a harmonia social, há de ser reservada àquelas situações características de total ausência quanto às possibilidades de solução pacífica, haja vista o necessário pragmatismo a consubstanciar a decisão judicial.

O reconhecimento da essência humana, em toda a sua complexidade, marcada pelas aventuras e desventuras da vida de cada ser, e os atos individuais ou coletivos praticados na busca de determinados interesses se entrechocam no decorrer da existência e, salvo melhor juízo, encontram manto protetor mais amplo, ou podem ser observados mais de perto e levados em consideração, sopesados mais cuidadosamente, quando os proprios indivíduos compõem-se na construção de solução a todos aceitável e viável, transmutando potenciais "perdas" pontuais em uma noção ou sentimento mais claro e palpável de realização do justo.

A fim de fixar uma compreensão mais apurada sobre "reconhecimento" busquemos os favores da literatura, novamente, para ilustrarmos exatamente o oposto do esperado conceito; a reprodução do trecho a seguir é do livro Infância, de Graciliano Ramos:

\footnotetext{
Havia uma neblina, e não percebi direito os movimentos de meu pai. Não o vi aproximar-se do torno e pegar o chicote. A mão cabeluda prendeu-me, arrastou-me para o meio da sala, a folha de couro fustigou-me as costas. Uivos, alarido inútil, estertor. Já então eu devia saber que rogos e adulações exasperavam o algoz. Nenhum socorro. José Baia, meu amigo, era um pobre-diabo. (...) sozinho, vi-o de novo cruel e forte, soprando, espumando. E ali permaneci, miúdo, insignificante, tão insignificante e miúdo como as aranhas que trabalhavam na telha negra. Foi esse o meu primeiro contacto que tive com a justiça.
}

O relato carrega a marca da violência. Mas uma violência até há pouco consentida, e certamente ainda praticada; apenas, imagina-se, em menor frequência que nos tempos de menino do escritor. Graciliano recebeu um "corretivo" do pai por conta de alguma traquinagem. $\mathrm{Na}$ visão do próprio garoto o pai lhe fez justiça, como ele mesmo afirma ao reconhecer na situação o seu "primeiro contacto" com a deusa cega.

Do episódio ainda é possível extrair a condição psíquica da criança: um sentir-se “insignificante" e "miúdo" diante da força e da fúria do pai. Impotente. Mais precisamente, humilhado. Nessa condição conheceu o menino a Justiça. $\mathrm{O}$ vazio, o perceber-se um nada é a antítese do conceito procurado; é o sinal da ausência de reconhecimento da pessoa. "O indivíduo se sente como olhado do alto, como se fosse nada. Privado de aprovação, é como se não existisse.” (RICOEUR, 2007, p. 310-311).

Necessário, portanto, "reconhecer" na existência do outro o primeiro passo à aplicação de métodos autocompositivos para a resolução de conflitos. Na mediação, recorte desta 
análise, em primeiro plano as partes devem reconhecer-se, ao contrário do caráter substituinte da jurisdição estatal, que "afasta a faculdade das partes de agir uma em relação à outra, cedendo espaço ao órgão estatal imparcial, investido na figura do juiz", como mencionado anteriormente. Na mediação, há a necessidade de deixar de lado a mentalidade canhestra fulcrada apenas na desconfiança ou na desvalorização do outro, o que não significa abdicar do que se imagina justo ou moral. A problemática toda se restringe à mudança de mentalidade. Se desde pequena a criança sente o peso da força, em seu sentido metafórico ou literal, no âmbito da própria família, como elemento primordial de resolução de conflitos, o padrão repetir-se-á na vida adulta. Replica-se, desta forma, a cultura da imposição, do vencedor e do vencido. Sabe-se que o "reconhecimento da criança no âmbito da entidade familiar é o fundamento para as outras relações que essa pessoa estabelecerá durante sua existência" (ALMEIDA, 2014, p. 2). Em relação ao amor familiar, oportuno o comentário de Axel Honneth (2003, p. 177):

[...] ele precede, tanto lógica como geneticamente, toda outra forma de reconhecimento recíproco: aquela camada fundamental de uma segurança emotiva não apenas na experiência, mas também na manifestação das próprias carências e sentimentos, propiciada pela experiência intersubjetiva do amor, constitui o pressuposto psíquico de todas as outras atitudes de autorrespeito.

Socorrendo-se de outro contumaz exemplo literário, lembra-nos Dostoiewiski, em seu Irmãos Karamazov: uma boa lembrança de infância, bem guardada, pode nos salvar a alma no futuro. Se a assertiva é verdadeira, seu reverso não deixa de ser válido - más lembranças quase sempre só servem para perpetuar a dor. Daí a primeira e precoce conclusão deste estudo: a mudança de paradigma se faz necessária. Métodos de solução de conflitos a privilegiar a relação dialógica dos indivíduos dependem do implemento da cultura da autonomia, do respeito ao indivíduo, ou seja, do reconhecimento do "outro" como pessoa.

Para tanto, são necessárias "ações orientadas para o entendimento mútuo", em que o ator social inicia o processo circular da comunicação e é produto dos processos de socialização que o formam, em vista da compreensão mútua e consensual. Como bem expõe Habermas (2003, p. 165), "o processo de entendimento mútuo visa a um acordo que depende do assentimento racionalmente motivado ao conteúdo de um proferimento. $\mathrm{O}$ acordo não pode ser imposto à parte, não pode ser extorquido ao adversário por meio de manipulações".

Ou seja, as partes que se propõe a participar de uma mediação, necessitam despir-se das ganâncias do agir estrategicamente, que compreende utilizar-se de práticas individualistas, 
de política da força e/ou de ações orientadas pelo interesse exclusivo do sucesso, visando um resultado de soma-zero ${ }^{7}$.

\title{
2. DIREITO, INDIVÍDUO E INDIVIDUALISMO
}

O indivíduo como sujeito de direitos surge com o jusnaturalismo moderno. Não é objeto deste trabalho discorrer sobre as dissensões entre jusnaturalistas e juspositivistas quanto a condição do ser humano sujeito de direitos. Adota-se para os fins desta análise a doutrina de José Reinaldo de Lima Lopes (2004, p.159):

\begin{abstract}
O indivíduo, segundo o jusnaturalismo, antes de qualquer condição, aparecia como portador de um direito, uma faculdade natural e moral, da qual se poderiam derivar consequências jurídicas. O ser humano individual determinado empiriricamente (um ser de necessidades), o indivíduo 'natural', passaria a ser o início, o ponto de partida do pensamento jurídico ocidental moderno.
\end{abstract}

Claro está que para ser sujeito de pelo menos um direito fundamental, o "direito de reconhecimento como ser humano" basta o indivíduo apresentar tal condição. O indivíduo como ser autônomo está "desligado de todo e qualquer vínculo social ou político" (DUMONT, 1991, p. 37). Quando o indivíduo exerce ideologicamente o comando de sua vida, escapa da condição de passividade do ser natural, e passa a cultivar o individualismo como faculdade mental. Assim, o conceito de indivíduo "está relacionado à mudança de atitudes e mentalidades que transformam a forma de pensar e agir dos homens e mulheres em relação a si próprios e aos outros" (ALMEIDA, 2014, p. 21).

Especificamente na sociedade ocidental, o ideologismo individualista é característica marcante, mormente ao comparar-se as sociedades consideradas holísticas, como a hindu ou a africana. Nestas últimas homem e mulher são compreendidos "não a partir de si próprios, mas por meio de sua inserção social" (DUMONT, 1991, p. 37).

Se admitirmos a vivência de tempos de pós-modernidade (pelo menos na sociedade ocidental), da chamada "modernidade líquida" baumaniana, modernidade reflexiva ou hipermodernidade, entre tantos termos designadores da mesma Era, constata-se a consagração do vínculo direto existente entre direitos humanos e individualismo (ALMEIDA, 2014, p. 22).

Se, por um lado, o reconhecimento do ser humano como "ser ideológico" revestido de características psicológicas singulares e necessidades próprias elevou a intelectualidade

\footnotetext{
${ }^{7}$ Resultados de soma zero são "aqueles nos quais um dos competidores, para ganhar, deve levar necessariamente o adversário à derrota" (ALMEIDA, 2003).
} 
humana a níveis até então desconhecidos, de outra feita corroborou à criação do "super ser humano", cada vez mais preocupado em suprir as próprias necessidades, atingir os próprios objetivos, realizar os próprios desejos. O homem, em sua individualidade se tornou o "referencial absoluto", nas palavras de Lipovetsky:

\begin{abstract}
A cultura hiperindividualista coincide com a desconfiança contra o político e com a consagração ideológica dos direitos humanos erigidos em fundamento último e universal da vida em sociedade. Sagração dos direitos humanos que completa o processo de reconhecimento do indivíduo como referencial absoluto, última bússola moral, jurídica e política de nossos contemporâneos desligados de todas as antigas formas de inclusão coletiva.
\end{abstract}

Diante desse ser humano hiperautônomo, pergunta-se: o que faz o indivíduo se tornar pessoa? Do ponto de vista antropológico, o "agir em relação umas às outras com espírito de fraternidade", conquanto da perspectiva jurídica, a pessoa se define "enquanto ser a quem se atribui direitos e obrigações" (ALMEIDA, 2014, p. 22). Sob os auspícios da mediação, como método de resolução de conflitos, questiona-se: àqueles concordantes à tentativa de solucionar determinado impasse pelo método autocompositivo mais interessam os direitos e deveres de cada qual ou a forma de se relacionar, de se reconhecer a outra parte?

Evidente em cada uma das partes, na hipótese apresentada, o sentimento moral de certeza quanto ao seu próprio direito de posse do objeto (material ou imaterial) pleiteado. $\mathrm{O}$ diferencial está no fato dessa "certeza" individual não excluir a "certeza" alheia. Mas como isso seria possível? Se tem-se convicção sobre determinado fato, esta exclui qualquer pleito a contrariá-la. É verdade, ao se pensar na contenda judicial acerca de determinado fato. Ou se está certo ou se está errado, do ponto de vista de um terceiro investido de poder para decidir.

Na mediação, ocorre o contrário; mesmo convicto de sua "própria razão", a parte não exclui o potencial de razão alheia; não é levada por uma fé cega ou vestal na estrutura moral do outro, mas compreende que, ao reconhecer o outro como pessoa, na acepção antropológica do termo, assim também é reconhecido. Não há invisíveis, não há insignificantes, não há miúdos, como o menino de Graciliano presente em nossas primeiras linhas.

Na mediação, tem-se, portanto, a resolução da totalidade da lide com a preservação das relações interpessoais e sociais, na sua concepção mais plena de justiça: a justiça coexistencial. Esta justiça, em contraponto com a visão tradicional de justiça, que tem como escopo anunciar um vencedor e um vencido, essa justiça não tem base na polarização do processo judicial por ser "tendente à obtenção de consenso, antes do que uma condenação, 
evitando o acirramento de ânimos entre pessoas que tenham que persistir convivendo, coexistindo na mesma comunidade, no mesmo meio"» (LIMA, 1994, p. 21).

A mediação não fica alheia ao fato de que as relações sociais são importantes para o processo de emergência do conflito, mas também para a sua resolução.

\title{
3. DESAFIO DO MEDIADOR: TRANSFORMAR INDIVÍDUOS EM PESSOAS
}

Manuais não faltam a estabelecer na forma de regras o que deve ou não fazer o mediador. Não obstante a importância desses escritos, a forma ou atuação pontual do mediador escapa ao objeto deste estudo. A nos interessar está a macropostura de tal ente. Repita-se: não se está a desprezar técnicas consagradas e erigidas por especialistas de maior calibre no campo deste saber. O que se pretende é mais singelo; espera-se tão-somente trazer à análise determinadas formas de ser e de agir do mediador, em um contexto holístico, capaz de expor as personalidades individuais das partes a fim de elas mesmas, auxiliadas, chegarem a um desfecho. É preciso dizer, de antemão: desfecho de mediação não implica, necessariamente, solução cabal e definitiva a determinado conflito:

\begin{abstract}
$\mathrm{Na}$ mediação, somente os mediandos são legítimos para saber qual é o melhor desfecho para o conflito. Ao contrário da jurisdição, a lei é somente uma referência, não uma condicionante.Isso porque a generalidade própria da previsão legal não pode observar as particularidades dos casos reais. A liberdade de criar soluções sem as amarras do ordenamento jurídico confere aos mediandos a autonomia de constituir suas próprias soluções não somente para enfrentar aquele conflito específico, como também para capacitá-los para uma boa gestão de conflitos futuros. O conceito de mediação comunitária para a emancipação social [...] rejeita a adoção da mediação exclusivamente como uma técnica de resolução de conflitos. Como prática comunitária transformadora - exercida na, para e pela comunidade -, a mediação se revela um importante instrumento de emancipação social quando associada ao exercício da educação para os direitos [...] Grifos do autor (FOLEY, 2014, p. 85).
\end{abstract}

Justamente afastado da mediação o rótulo de ser apenas uma técnica de resolução de conflitos, encontrar-se-á a sua importância maior. Trata-se de prática a possibilitar resultados muito mais valiosos no sentido da denominada autonomia social. Para Warat (2004),

[...] o objetivo do direito não é o de alcançar a paz social, nem de aplicar a lei, nem de distribuir justiça, mas o de resolver a humanização dos conflitos, entendendo por humanização a possibilidade de escapar da alienação (em muitos casos determinadas

\footnotetext{
${ }^{8}$ LIMA, Cláudio Vianna de. Arbitragem: a solução, p. 21.
} 
pelo próprio direito) e propiciar as condições de produção e realização existencial da autonomia. Estou também admitindo, inicialmente, que a filosofia não realiza as condições da autonomia (pelo contrário, em muitos casos a põe em risco), que precisa de indivíduos definitivamente instalados na experiência e na pedagogia. Indivíduos com a suficiente sabedoria para poder aprender com a experiência e depois traduzir essa aprendizagem em uma expressão filosófica. Falar de autonomia não como emancipação dos socialmente excluídos, mas como possibilidade de adquirir, na vida, um movimento próprio, sem dependências ou submissões ao movimento dos outros.

Dentro desta visão, há o estímulo, portanto, à consciência crítica do cidadão e ao seu perceber o outro tal como a si mesmo é propulsor de pensamento apto a romper o atual paradigma de decisões estanques e escalonadas, baseadas em fórmulas predefinidas a descartar as necessidades de cada ser.

Pessoas assumem, em uma relação dialógica, novo protagonismo social, fruto do “empoderamento" (FOLEY, 2014, p. 85) resultante da experiência de argumentar e ouvir os argumentos do outro. Em progressão geométrica, a mediação deixa de ser uma mera técnica para transformar a sociedade:

\footnotetext{
Essa perspectiva se encontra alinhada ao conceito de mediação para uma comunidade participativa (VEZZULLA, 2013), pela qual o mediador não pode solucionar os conflitos no lugar das pessoas, assim como não pode desenhar a comunidade como ela deveria ser, a partir de uma ideologia que lhe seja exógena. Se assim o fizer, negará à comunidade a sua condição de sujeito, transformando-a em objeto e perpetuando as suas relações de dependência em relação a algum "iluminado" que, por seu saber científico ou por sua liderança, acredita saber o que é melhor para a comunidade. (FOLEY, 2014, p. 87)
}

Dessa perspectiva, a primeira característica do mediador deve dizer com a postura do acolhimento. Há de se levar em altíssima conta o fato de duas ou mais pessoas afastarem a priori o viés belicoso de um conflito, abrindo mão do confronto da jurisdição em prol da autonomia da argumentação. Em tese, pode parecer simplesmente um gesto simpático, politicamente correto, mas não olvide-se todas as dificuldades do caso concreto. Tomando como exemplo um caso de separação conjugal ou a questão de guarda de filhos, não há de se descartar o caldo de sentimentos a efervescer na cabeça de cada uma das partes; dor, decepção, julgamento moral, reminiscências de alegrias e sofrimentos.

Nada disso passa incólume do plano da emoção para o plano da razão. Vidas não se põem à mesa de discussão para serem dissecadas, analisadas ou esquecidas. E o mediador deve trazer consigo o sentimento de cuidado. Acolher, portanto, é a primeira tarefa. Mas tal acolhimento deve ser sentido, captado pelas partes. Só desta maneira abrir-se-ão canais comunicativos capazes de penetrar as barreiras erguidas pelos sentimentos pessoais. 
O próximo passo, instalada a mediação, é não ter pressa. Superado o primeiro obstáculo dos anteparos emocionais, há necessidade de se identificar os denominados "pontos de bifurcação":

\begin{abstract}
Nessas circunstâncias, o operador - mediador, consultor ou facilitador - consciente do papel construtivo desses processos, estará atento aos novos eventos, às variações, aos momentos críticos ou pontos de bifurcacão que oferecem opções, aos elementos capazes de articular criativos processos de auto-organização. Quando o operador encontra o elemento articulador, envolve-se facilitando o diálogo e as oportunidades que emergem do próprio processo. Tais circunstâncias favorecem a criação de plataformas inéditas e inesperadas a partir do mesmo processo construtivo; as flutuações, o acaso, e a criatividade fazem parte desse processo. Os modelos enquadrados nos novos paradigmas integram a ênfase pragmática às destrezas e soluções com uma preocupação pelos processos emergentes (SCHNITMAN, 1999, p. 20). Grifo nosso.
\end{abstract}

Parece-nos verossímil constatar nesses pontos de bifurcação mais que elementos discrepantes e originais do conflito. Eles têm potencial para contornar o caminho, a via principal, a estrada asfaltada. Uma vereda, de terra batida, às vezes é mais difícil de ser percorrida, porém o caminho pode se apresentar mais curto e menos congestionado.

As turbulências e oscilações as quais todos nós estamos sujeitos podem apontar para novas formas de comunicação e entendimento. A criatividade, o futuro aberto, o afastamento das visões exclusivas e a construção de marcos universais unificadores podem conduzir a sociedade a um novo patamar de Justiça. Esse tipo de justiça está mais destinada a repensar o litígio e não a decidir e definir, isso com o objetivo de aliviar as situações, vislumbrando um valor maior: a preservação de um bem durável, a preservação da convivência dos sujeitos que fazem parte de um grupo ou que possuam relações complexas. Essa preocupação não é inerente à justiça tradicional, que "olha mais para o passado do que para o futuro" (CUNHA, 2002), diferentemente da justiça coexistencial, que se preocupa com a conservação das instituições integrais. Com muita propriedade destaca o professor José Renato Nalini, em artigo publicado no jornal Folha de S.Paulo:

[...] edificar uma cultura de pacificação não atende exclusivamente à política de reduzir a invencível carga de ações cometidas ao Judiciário. O aspecto mais importante é o treino da cidadania a ter maturidade para encarar seus problemas com autonomia, situação muito diversa da heteronomia da decisão judicial. (Artigo publicado na Folha de S.Paulo, em 09/03/2014, intitulado Justiça é obra coletiva)

E, por fim, antes de seguir adiante e apresentar as conclusões deste trabalho, ressaltese as palavras de Warat (2004): “[...] algumas coisas de nossa existência não podem ser 
corrigidas por atos de legislação e receitas pré-escritas (sic) pela razão. Hoje não se espera mais encontrar salvação em fórmulas totais, únicas."

\section{CONCLUSÃO}

O norte da prática da mediação é o "reconhecimento" da pessoa no sentido antropológico do termo; quer dizer, a valorização do agir em relação uma à outra com espírito de fraternidade.

Esse "reconhecimento" pode ser traduzido ou entendido como consideração à pessoa alheia e aos seus pontos de vista, fato capaz de elevar as discussões em torno de determinado conflito em uma relação dialógica, despida de qualquer relação de força ou poder que torne submissiva uma parte à outra.

O primeiro dever do mediador é desenvolver a capacidade de "acolhimento" das partes em conflito, especificamente aquele gerado a partir de situações que potencializam o estresse emocional gerado pela fragilização de sentimentos e emoções pessoais relativos uns aos outros.

A resolução de um determinado conflito, apesar de figurar como um dos elementos centrais não é, por si só, o objetivo único da mediação. Esta contempla um espectro mais abrangente, que diz com a capacidade do ser humano de resolver seus próprios problemas sem as fórmulas predeterminadas da legislação, e no sentido da construção de uma sociedade autônoma.

O reconhecimento do outro perpassa pelo diálogo aberto, evitando no processo de resolução do litígio ações estratégicas e resultados de soma-zero. A mediação envolve um processo de diálogo, de ações orientadas para o entendimento mútuo, baseada na comunicação.

O processo de resolução de conflitos por meio da mediação afasta-se da concepção tradicional de justiça, que visa apenas decidir a lide, dizendo o direito, para aproximar-se da ideia de justiça coexistencial, que priora a resolução da lide, e a preservação das relações interpessoais e sociais, na sua concepção mais plena de justiça.

\section{REFERÊNCIAS}


ALMEIDA, Fábio Portela Lopes de. A teoria dos jogos: uma fundamentação teórica dos métodos de resolução de disputa. In. AZEVEDO, André Gomma de. Estudos de Arbitragem Mediação e Negociação, Vol. 2, 2003. Disponível em: <www.arcos.org.br/ livros/estudos-dearbitragem-mediacao-e-negociacao-vol2/terceira-parte-artigo-dos-pesquisadores/a-teoria-dosjogos-uma-fundamentacao-teorica-dos-metodos-de-resolucao-de-disputa>. Acesso em: 10 ago. 2015.

ALMEIDA, Guilherme Assis de. Mediação e reconhecimento da pessoa. Revista da Associação dos Advogados de São Paulo, n. 123.Agosto de 2014. São Paulo: AASP.

CUNHA, J. S. Fagundes. Da mediação e da arbitragem endoprocessual. Disponível em: <http://www.fagundescunha.org.br/artigos/DA\%20MEDIA\%C7\%C3O\%20E\%20DA\%20AR BITRAGEM\%20ENDOPROCESSUAL.pdf>. Acesso em: 10 ago. 2015.

DOSTOIEVSKI, Fiodor M. Os irmãos Karamazovi. Tradução de Natália Nunes e Oscar Mendes. Rio de Janeiro: Cia Aguilar. 1970, 535 p.

DUMONT, Louis. Essais sur l'iindividualisme: une perspective anthropologique sur l'ideologie moderne. Paris: Gallimard, 1991. (Collection Folio Essais, 230).

FOLEY, Gláucia Falsarella. Mediação comunitária para a emancipação social. Revista da Associação dos Advogados de São Paulo, n. 123.Agosto de 2014. São Paulo: AASP.

HABERMAS, Jürgen. Consciência moral e agir comunicativo. 2 ed. Rio de Janeiro: Tempo Brasileiro, 2003.

HONNETH, Axel. Luta por reconhecimento: a gramática moral dos conflitos sociais. Tradução de Luiz Repa. São Paulo: Editora 34, 2003.

LIMA, Cláudio Vianna de. Arbitragem: a solução. Rio de Janeiro: EMERJ, 1994.

LIPOVETSKY, Gilles. Os tempos hipermodernos.Tradução de Mário Vilela. São Paulo: Barcarolla, 2004.

LOPES, José Reinaldo de Lima. As palavras e a lei: direito, ordem e justiça na história do pensamento jurídico contemporâneo. São Paulo: Editora 34; Edesp, 2004. (Coleção Direito GV). 
NALINI, José Renato. Justiça é obra coletiva. Artigo publicado no jornal Folha de S.Paulo.9 de março de 2014.

RAMOS, Graciliano. Infância. 35 ed. Rio de Janeiro: Record, 2002.

RICOUER, Paul. Parcours de la reconnaissance: trois études. Paris: Gallimard, 2007. (Collection Folio Essais, 459)

SANTOS, Boaventura de Sousa; MARQUES, Maria Manuel Leitão; PEDROSO, João. Os tribunais nas sociedades contemporâneas. Disponível em: <www.anpocs.org.br/portal/publicacoes/rbcs_00_30/rbcs30_07.htm>. Acesso em: $10 / 08 / 2015$.

SILVA, Adriana S. Arbitragem e Acesso à Justiça: uma caminho para a crise do Judiciário. Barueri: Manole, 2015.

SCHNITMAN, Dora Fried: LITTLESOHO, Stephen (Org.). Novos paradigmas em mediação. Porto Alegre: Artmed, 1999

WARAT, Luis Alberto. A cidadania e direitos humanos da qualidade total. In. Revista da Escola da Magistratura do Estado de Rondônia, $\mathrm{n}^{\circ}$ 12, ano 2004. Disponível em: http://emeron.tjro.jus.br/images/biblioteca/revistas/revista-emeron-12-2004.pdf\#PAGE=41. Acesso em: 15 ago. 2015. 